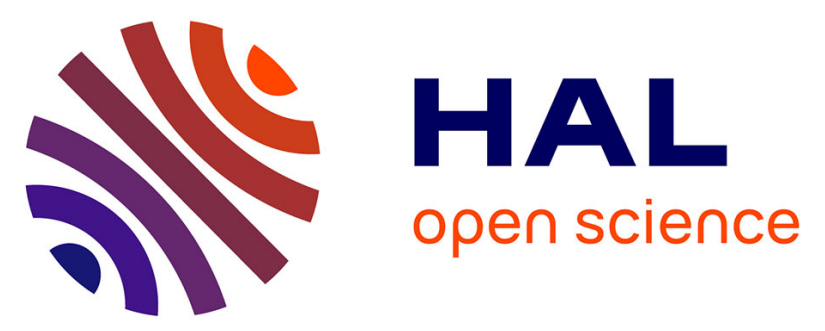

\title{
CHARACTERIZATION OF HOMOGENOUS AND PLASTICALLY GRADED MATERIALS WITH SPHERICAL INDENTATION AND INVERSE ANALYSIS
}

Charbel Moussa, Olivier Bartier, Gerard Mauvoisin, Philippe Pilvin, Guillaume Delattre

\section{To cite this version:}

Charbel Moussa, Olivier Bartier, Gerard Mauvoisin, Philippe Pilvin, Guillaume Delattre. CHARACTERIZATION OF HOMOGENOUS AND PLASTICALLY GRADED MATERIALS WITH SPHERICAL INDENTATION AND INVERSE ANALYSIS. Journal of Materials Research, 2012, 27 (1), pp.20-27. 10.1557/jmr.2011.303 . hal-00996465

\section{HAL Id: hal-00996465}

\section{https://hal-univ-rennes1.archives-ouvertes.fr/hal-00996465}

Submitted on 26 May 2014

HAL is a multi-disciplinary open access archive for the deposit and dissemination of scientific research documents, whether they are published or not. The documents may come from teaching and research institutions in France or abroad, or from public or private research centers.
L'archive ouverte pluridisciplinaire HAL, est destinée au dépôt et à la diffusion de documents scientifiques de niveau recherche, publiés ou non, émanant des établissements d'enseignement et de recherche français ou étrangers, des laboratoires publics ou privés. 


\title{
CHARACTERIZATION OF HOMOGENOUS AND PLASTICALLY GRADED MATERIALS WITH SPHERICAL INDENTATION AND INVERSE ANALYSIS
}

\author{
Moussa Charbel, Bartier Olivier, Mauvoisin Gérard , Pilvin Philippe , Delattre \\ Guillaume
}

This study investigates spherical indentation of plastically graded materials (PGM). The hardness of these materials decreases with depth due to micro-structural or compositional changes. In order to predict the behaviour of PGM, the knowledge of the plastic properties of the surface and the substrate is necessary. In this work, the spherical indentation technique is applied on carbonitrided steels in order to obtain their mechanical properties.

First, spherical indentation was applied to characterize homogenous materials using inverse analysis. The comparison with tensile test's results shows that the inverse analysis using spherical indentation data is a reliable method to determine the plastic properties of homogeneous materials. In a second part spherical indentation was used to characterize carbonitrided steels using inverse analysis in order to obtain plastic properties of the surface. The results show that spherical indentation using inverse analysis has a real potential for evaluating mechanical properties of PGM.

\section{INTRODUCTION}

Surface treatments (carbonitriding, carburizing ...) are highly used in industry since they greatly improve the hardness of the material's surface. Surface treated materials have a high hardness on surface and a decreasing hardness profile with depth but have constant elastic properties. These materials are commonly called plastically graded materials (PGM). The knowledge of the mechanical properties of PGM is necessary for the prediction of the mechanical behavior of many engineering parts such as gears and rollers. On such materials, a standard tensile test cannot be applied to obtain their mechanical properties. The indentation technique is increasingly used to determine mechanical properties of materials. ${ }^{1-10}$ This technique can be used to characterize the graded plastic properties of PGM because it characterizes locally the material from only a small volume of material. Moreover, the indentation test needs no or very simple sample preparation. Fewer studies were made on indentation of PGM than on homogenous materials. Two different procedures can be applied to characterize PGM. The first one consists to perform many tests in the section of the sample. 11. The second one consists to make only one indentation test at the surface and then to apply a mixture law. ${ }^{12-23}$

Applying the first procedure, Branch et al. ${ }^{11}$ have recently proposed a method to characterize PGM. They first applied a macro-Vickers indentation on the surface. The macro-Vickers indent was then sectioned and polished to the indent diagonal which corresponds to the plane of maximum indent and plastic zone depths. Then they performed micro-Vickers indentations along the centerline of the macro-indent's plastic zone. Then, with the assumption about the evolution of the strain hardening exponent, the increase in yield strength was predicted using finite element modeling. The drawback of this method is its complexity. Another 
disadvantage is that the uniqueness of the evolution of the hardening exponent proposed by the authors is not guaranteed.

More studies were made according to the second procedure and most of them are proposed for conical indentation.

Gianakopoulos ${ }^{12}$ used nonlinear elasticity and the slip line theory to propose an analytical model for sharp indentation. However, the proposed model is limited to non-linear elastic substrates with power law variation of strain hardening or rigid plastic substrates with a linear variation of yield stress.

Choi et al. ${ }^{13,14}$ used dimensionless functions proposed for homogenous elastic materials ${ }^{24}$ and homogeneous elastic-plastic materials ${ }^{15}$ to create a new dimensionless function which predicts the indentation loading curve of PGM using conical indenter. Experimental validation was conducted on nanocrystalline alloys by Choi et al. ${ }^{14}$. The drawback of this study is that the case of a linear gradient in yield stress with no spatial variation in strain hardening exponent is considered.

These methods were proposed for specific graded materials, thus they cannot be used to characterize carbonitrided steels. They were proposed either for perfectly plastic materials or for materials with no variation of the strain hardening exponent. More studies were made on the indentation of a hard film on a substrate ${ }^{17-19}$ than on graded materials. The case of hard film on a substrate is different from the case of carbonitrided steels.

Fisher-Cripps ${ }^{25}$ and VanLandingham ${ }^{26}$ presented many drawbacks of conical indentation such as the rounded tip of the indenter.

Spherical indentation does not present these drawbacks and is known to better avoid the uniqueness problem.

Nayebi et al. ${ }^{20}$ used a mixture law proposed by Battacharya and nix ${ }^{27}$ to develop a model for PGM such as carburized steels using spherical indentation. This model can be used to determine the plastic properties of the surface as well as the thickness of the surface and the intermediate layer. In this model, the authors made the assumption that the strain hardening exponent $\mathrm{n}$ does not vary with depth. No pile-up or sink-in is considered in this model.

PGM 's characterization is complicated because there are many parameters to determine.

The few proposed models present some difficulties to characterize carbonitrided steels. Either they are proposed for rigid plastic substrates or for materials with no variation of the strain hardening exponent. Moreover, these methods are based on many assumptions and some of them suffer of the drawbacks of conical indentation.

The inverse analysis method can be used to characterize the materials from indentation data. It is a high time consuming method but does not necessitate the development of a model that links indentation data with material properties. Applied with spherical indentation data, the inverse analysis avoids all the complications, assumptions and inaccuracy that are encountered in the available methods.

Nakamura et al. ${ }^{21,22}$ used inverse analysis (Kalman filter) to characterize Young's modulus of a graded material in which the fraction ceramic/steel varies with depth. Knowing Young's modulus of both constituents, the authors have determined the parameter of a mixture law to obtain the variation of Young's modulus with depth. Experimental verification of this method was conducted by Gu et al. ${ }^{23}$ The application of the inverse analysis to characterize this type of material is different from the case of carbonitrided steels because the unknowns of the two problems are different.

The aim of this paper is the determination of plastic properties of carbonitrided steels.

This paper is divided into two parts: in the first part, two homogenous materials (virtual and real) were characterized with spherical indentation using inverse analysis and the results were compared to those obtained by a tensile test. The aim of this part is to assess that a 
homogenous material, with Hollomon hardening power law can be correctly characterized by this method.

In the second part, two PGM were characterized with inverse analysis using spherical indentation data. Results obtained in this part were verified by comparing measured hardness and calculated ones using a model proposed by Gao et al. ${ }^{28}$ from the characterized values of the yield stress and the hardening exponent.

\section{INDENTATION BENCH}

The experimental indentation tests were carried out by using an indentation instrumented bench designed and produced within our laboratory. A load cell measured load with a resolution of $0.02 \mathrm{~N}$ and the displacement was measured thanks to capacitive sensors which were fixed near the indenter. This gives the distance between the indenter and the indented surface of the tested material with a resolution of $0.02 \mu \mathrm{m}$. The experimental system enables a maximum load equal to $1000 \mathrm{~N}$ to be applied. The tests were carried out with a spherical indenter of radius $R=0.5 \mathrm{~mm}$ and the displacement rate was about $2 \mu \mathrm{m} / \mathrm{s}$. Details of the experimental bench and its load frame compliance are given in Bartier et al. ${ }^{29}$

\section{FINITE ELEMENT MODEL}

An axisymetric two-dimensional finite element model (Fig. 1) was built up to simulate the indentation response of PGM. The radius of the whole model was set large enough so that there would be no effects of outer boundary. Along the bottom of the steel substrate, nodal displacements were constrained in the vertical direction. Element type CAX4 (four nodes axisymetric) is used with 10157 elements for the sample and 2035 for the indenter. At the contact area the elements' size is about $3 \mu \mathrm{m}$. A $1 \mathrm{~mm}$ diameter spherical carbide tungsten indenter was modeled.

The indenter is considered elastic with Young's modulus $E=600 \mathrm{GPa}$ and Poisson's ratio $v=$ 0.23 .

The constitutive model of the elastic-plastic indented material was taken to follow the well known $\mathbf{J}_{2}$ associated flow theory with rate-independent deformation. The elastic-Hollomon power-law hardening hypothesis was adopted in our study. Elastic properties of the studied materials were considered $E=210 \mathrm{GPa}$ and $v=0.3$. The friction coefficient was fixed at 0.1 . 

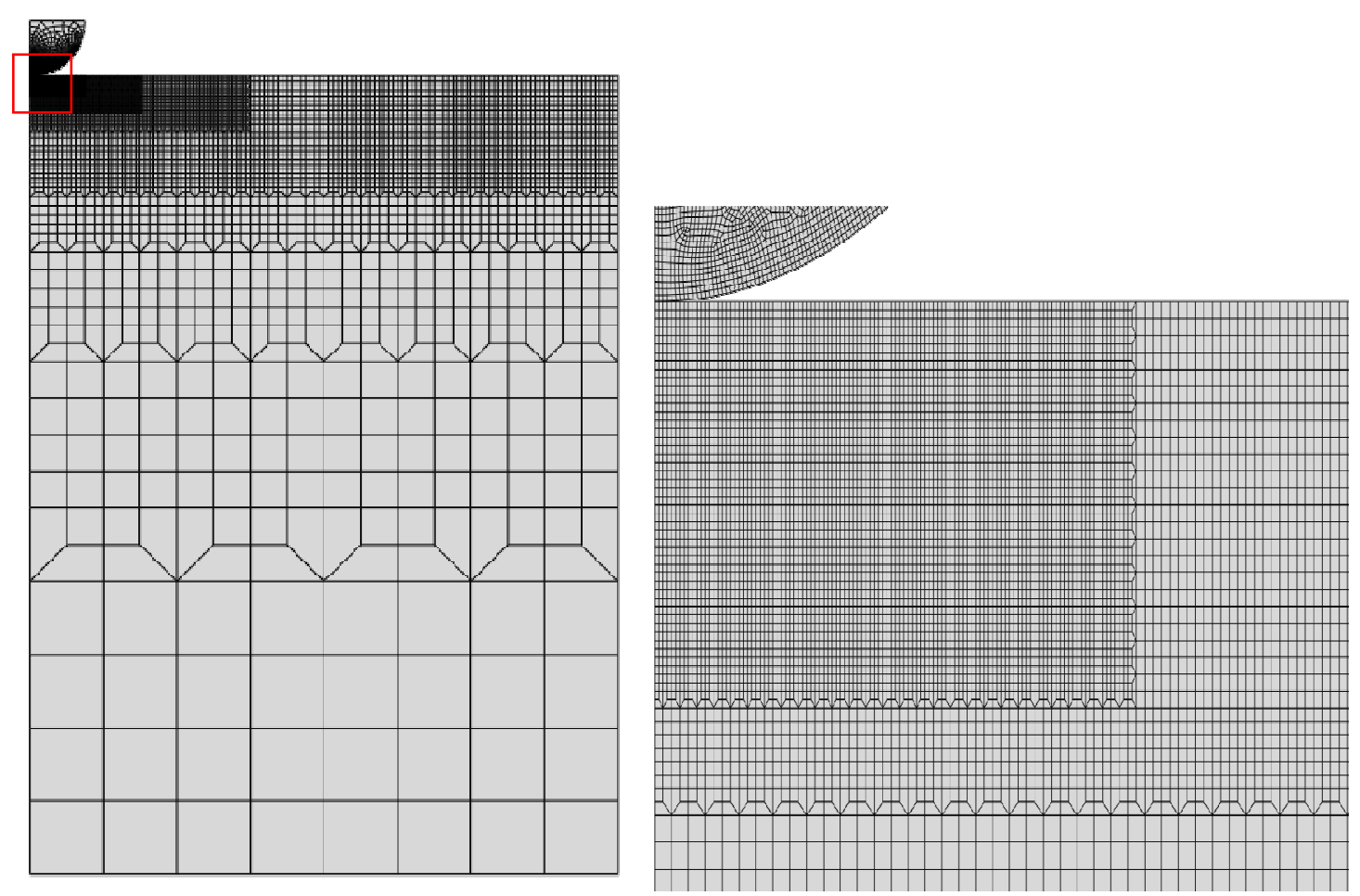

FIG.1: The mesh used in the finite element calculations.

\section{INVERSE ANALYSIS}

The inverse analyses method is based on the minimization of the cost functional measuring the difference between experimental and numerical data. In this study, the software SiDoLo ${ }^{30}$ was used for inverse analysis. In our case the goal is to obtain the plastic properties that give the minimum of the cost functional. Its expression is as follow:

$$
L(A)=\frac{1}{h_{f}} \int_{0}^{h_{f}}\left(F_{\text {exp }}-F_{\text {num }}(A)\right)^{2} d h
$$

Where $F_{\text {exp }}$ is the load obtained from experimental measurement, $F_{n u m}(A)$ is the load obtained from simulation for a specific set of parameters and $h$ is the penetration depth.

For the optimization, the software SiDoLo uses a hybrid algorithm that combines three classical techniques of minimization: the gradient method, the Newton-Raphson method and the Levenberg-Marquardt method.

\section{CASE OF HOMOGENOUS MATERIALS}

In this section, a virtual homogenous material was first characterized in order to study the convergence of the inverse analysis software and to prove the uniqueness of the solution. Then a real material was characterized with both tensile test and spherical indentation test and then the results were compared.

\section{A. Virtual material}

The plastic properties of the studied material are $\sigma_{y}=349 \mathrm{MPa}$ and $n=0.159$. Those plastic properties were chosen because they should be close to the typical values of the substrate of the $\mathrm{C} 18$ carbonitrided steel. 
Some typical evolution paths of the convergence procedure, showing the successive solutions given by the software, are plotted in Fig. 2.

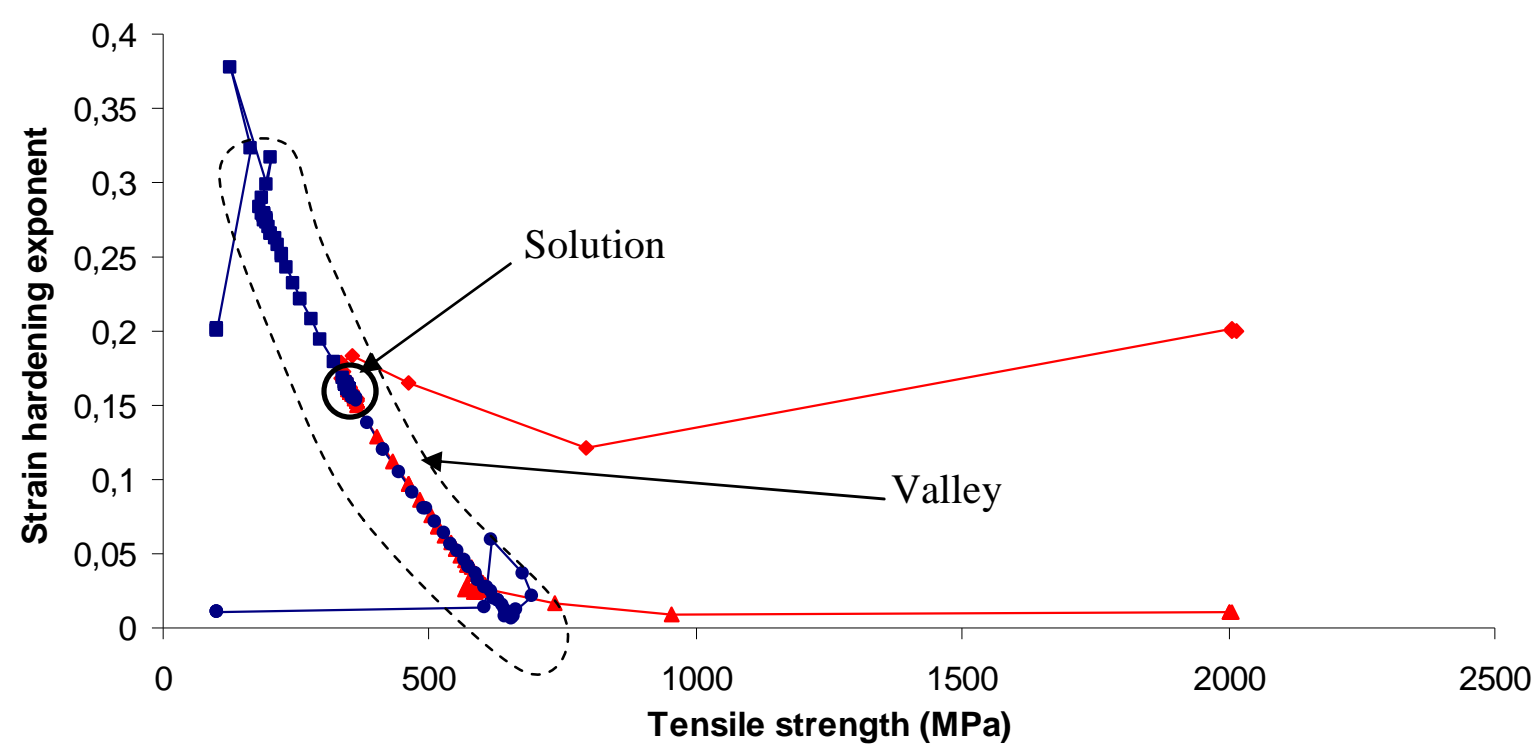

FIG. 2: Typical evolution path of the algorithm starting from 4 different corners for a virtual material ( $\sigma_{y}=349 \mathrm{MPa}$ and $\left.n=0.159\right)$.

Fig. 2 shows that the results obtained are independent from the starting point. A valley in which the cost functional varies very little is observed. It is noticed that the software converges easily to the solution if the starting point is perpendicular to this valley. The obtained plastic parameters and the costs functional are given in Table I.

\begin{tabular}{llllll}
\hline \hline Starting & $\sigma_{y}(\mathrm{MPa})$ & 2000 & 2000 & 100 & 100 \\
values & $n$ & 0.2 & 0.01 & 0.2 & 0.01 \\
\hline \multirow{3}{*}{ Solution } & $\sigma_{y}(\mathrm{MPa})$ & 361 & 362 & 351 & 361 \\
& $n$ & 0.154 & 0.154 & 0.160 & 0.154 \\
& Cost functional $\left(\mathrm{N}^{2}\right)$ & 0.362 & 0.188 & 2.85 & 0.245 \\
\hline \hline
\end{tabular}

TABLE I: Identification results with the correspondent cost functional values and starting values obtained for a virtual material ( $\sigma_{y}=349 \mathrm{MPa}$ and $n=0.159$ ).

The values of plastic properties, obtained by inverse analysis using spherical indentation data, are almost the same as those of the virtual material. We can conclude that the determination of the plastic properties of homogenous materials is satisfying by using this method.

\section{B. Real material}

In this part, a non-treated C18 steel is characterized. As shown in Fig. 3, this material presents a mixture of ferrite grains and fine cementite carbides. This type of steel, with a fine and homogeneous microstructure, leads to a good reproducibility of the indentation tests. 


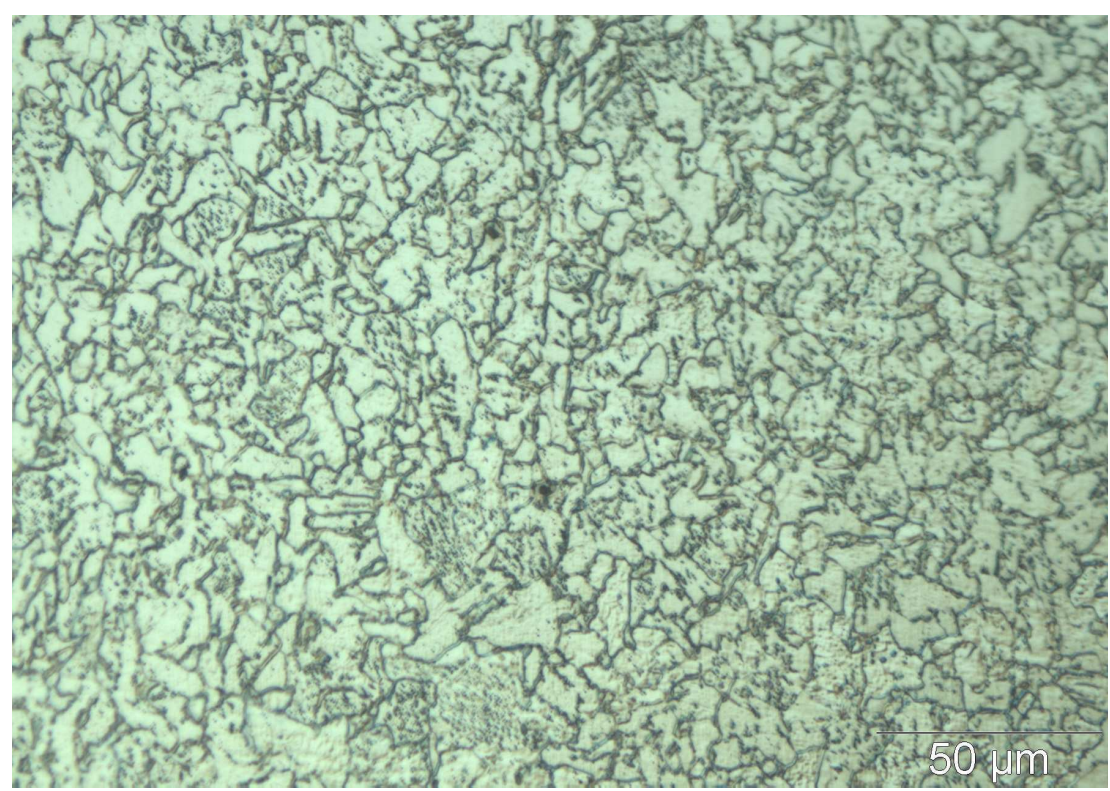

FIG.3: Microstructure of the non-treated C18 steel.

Tensile test was performed on the non-treated C18 steel. During the test, the strains were measured by using the mark-tracking method ${ }^{31}$. The strain rate is about $6.7 .10^{-4} \mathrm{sec}^{-1}$ and the numerical images were stored with a rate of 1 image per second. Tensile specimens with a 35 $\mathrm{mm}^{2}$ rectangular section and an effective length of $50 \mathrm{~mm}$ were tested. The stress-strain curve obtained with tensile test is shown in Fig. 4.

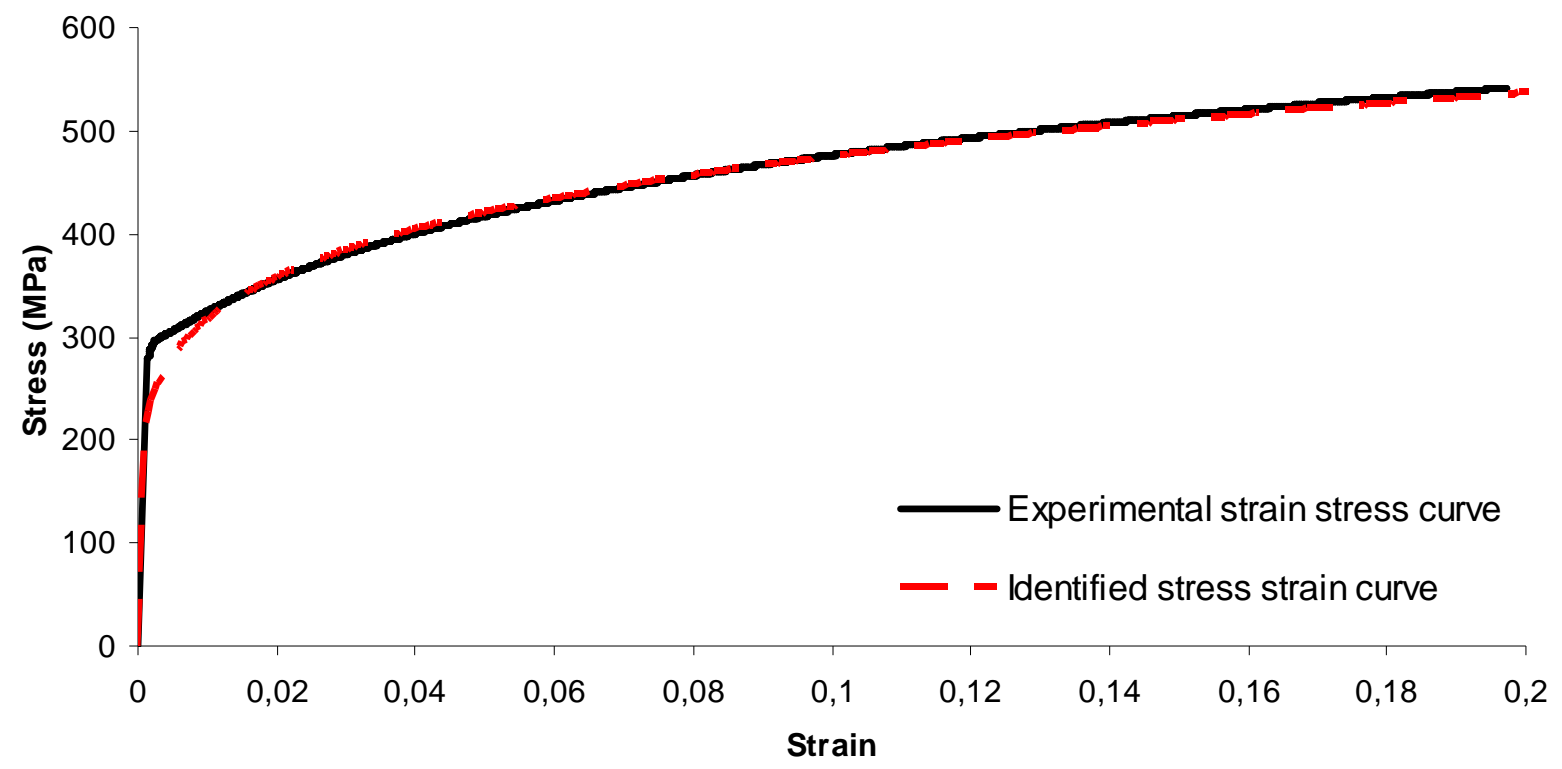

FIG.4: Comparison between strain stress curves obtained with a tensile test and with spherical indentation using inverse analysis for the non-treated C18 steel.

Fig. 5 shows the experimental indentation curve and the numerical one obtained from inverse analysis. The plastic properties obtained are $\sigma_{y}=211 \mathrm{MPa}$ and $n=0.176$ and the value of the cost functional is $0.35 \mathrm{~N}^{2}$ for $h / R=0,18$. 


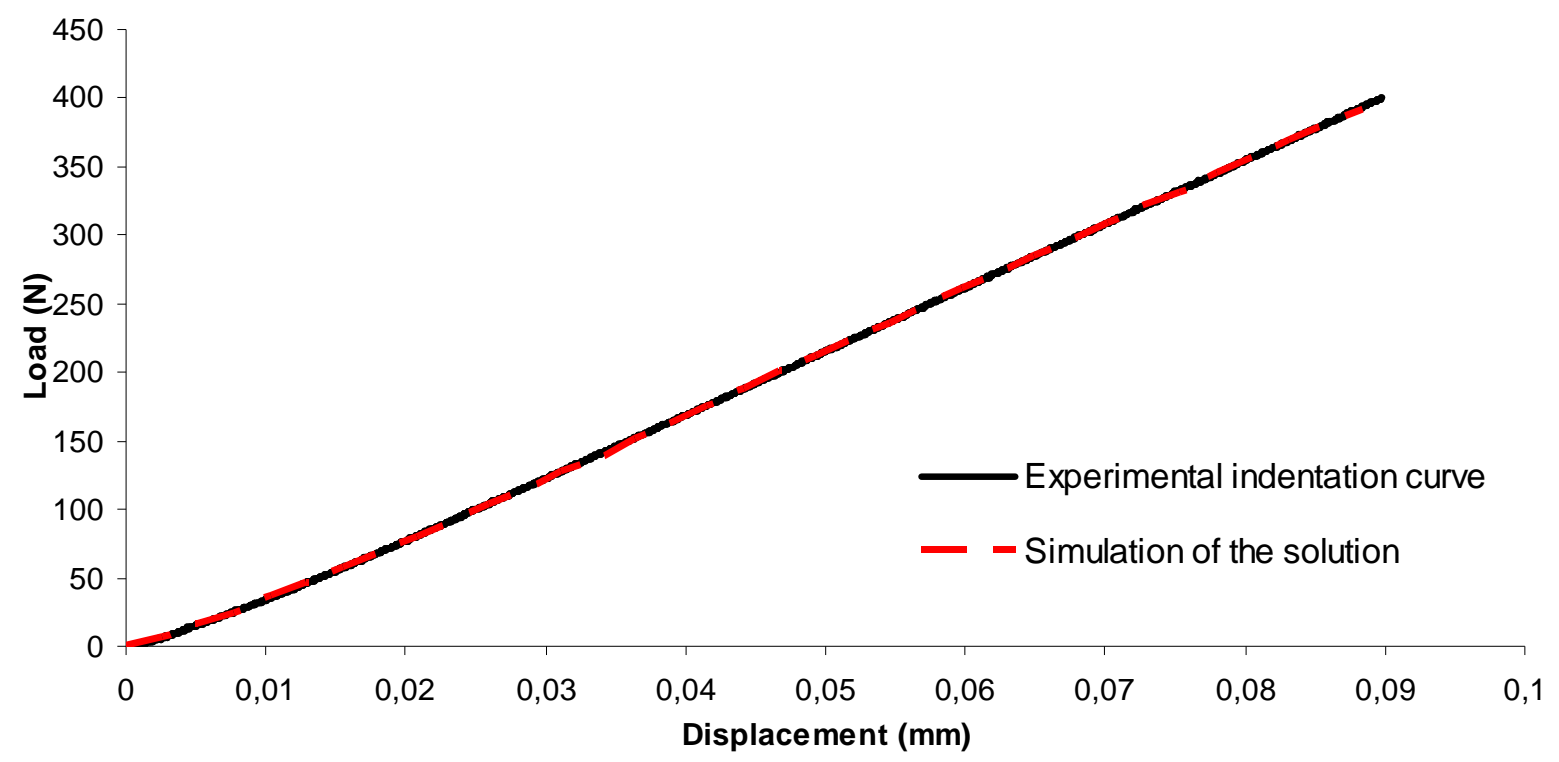

FIG.5 : Comparison between experimental and numerical indentation curves of non-treated C18 steel.

Fig. 4 compares the stress strain-curve obtained from tensile test and spherical indentation test. This figure shows that the two curves are very close.

The results obtained in this section show that the inverse analysis using spherical indentation data is a reliable method to determine the plastic properties of homogeneous materials.

\section{VI.- CASE OF PLASTICALLY GRADED MATERIALS (PGM)}

\section{A. PGM's characterization procedure}

In this part, a procedure was applied to characterize two different PGM: a carbonitrided not quenched C18 steel and a carbonitrided C18 steel. Those two materials were chosen because they present a very different hardness profile. The decreasing hardness profile of carbonitrided steels can be approximated by three straight lines. In the first zone of thickness $e_{1}$, the hardness is constant and is equal to the surface hardness. In the second zone of thickness $e_{2}$, the hardness presents a regular decreasing, and can be approximated by an inclined line. Finally, the third zone corresponds to the substrate, where the hardness is constant. The variation of the plastic properties is approximated in the same way. Fig. 6 shows the variation of the stress strain curves with depth. This variation was considered linear in the intermediate layer as described below:

$$
\begin{array}{lr}
\sigma=\sigma^{\text {surface }} & \text { for } z<e_{1} \\
\sigma=\sigma^{\text {substrate }}+\frac{\sigma^{\text {surface }}-\sigma^{\text {substrate }}}{e_{2}}\left(e_{2}+e_{1}-z\right) & \text { for } e_{1}<z<e_{2}+e_{1} \\
\sigma=\sigma^{\text {substrate }} & \text { for } z>e_{2}+e_{1}
\end{array}
$$

where, for each plastic strain, $\sigma^{\text {substrate }}$ is the stress of the hardening law of the substrate, $\sigma^{\text {surface }}$ is the stress of the hardening law of the surface, $e_{1}$ is the thickness of the surface layer, $e_{2}$ is the thickness of the intermediate layer and $z$ is the distance from surface. 


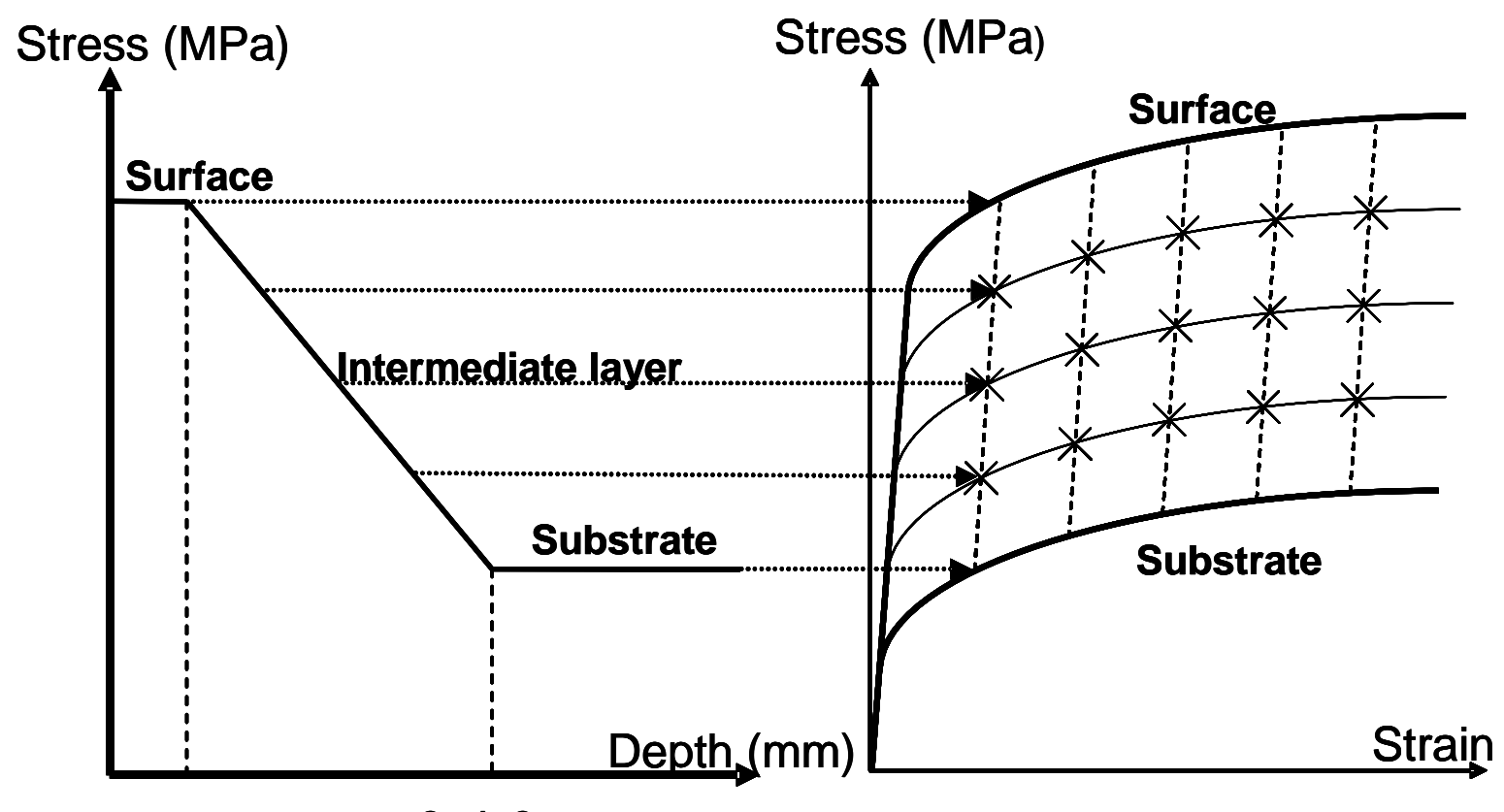

e1

$\mathrm{e}_{2}+\mathrm{e}_{1}$

FIG.6: Variation of the stress considered for a given plastic strain value in PGM.

After cutting the sample, a spherical indentation test was performed on the substrate. Then, the plastic properties of the substrate, assumed to be homogeneous, were obtained thanks to the inverse analysis. The thicknesses $e_{1}$ and $e_{2}$ were estimated from the measured hardness profile. The only unknown parameters left are the yield stress $\sigma_{y}$ and the strain hardening exponent $n$ of the surface layer. Thus, as for homogeneous material, the problem presents two unknown parameters. A spherical indentation test was performed on the hardened surface and inverse analysis was applied to find those two parameters.

The Vickers hardness calculated from the Gao et al. ${ }^{28}$ formulation was then compared to the measured one. This comparison was used to validate the results of the characterization.

Gao et al. ${ }^{28}$, using the expanding cavity model for strain hardening material that follow the Hollomon power law relationship, developed a relationship between hardness $H$, yield strength $\sigma_{y}$, strain hardening exponent $n$ and Young's modulus $E$ for Vickers indentation as:

$$
\frac{H}{\sigma_{y}}=\frac{2}{3}\left[\left(1-\frac{1}{n}\right)+\left(\frac{3}{4}+\frac{1}{n}\right)\left(\frac{1}{3} \frac{E}{\sigma_{y}} \cot \alpha\right)^{n}\right]
$$

Where $\alpha$ is the half included angle of the equivalent cone to the Vickers indenter.

\section{B. Carbonitrided not quenched C18 steel}

A metallographic analysis (Fig.7(a)) indicates that the substrate presents a mixture of ferrite grains and fine carbides. It is noticed that the structure of the substrate is very similar to the non-treated steel. Fig. 7(b) shows the microstructure of the surface. The increase in carbone fraction in the surface layers has for consequence the increase in carbide fraction. 


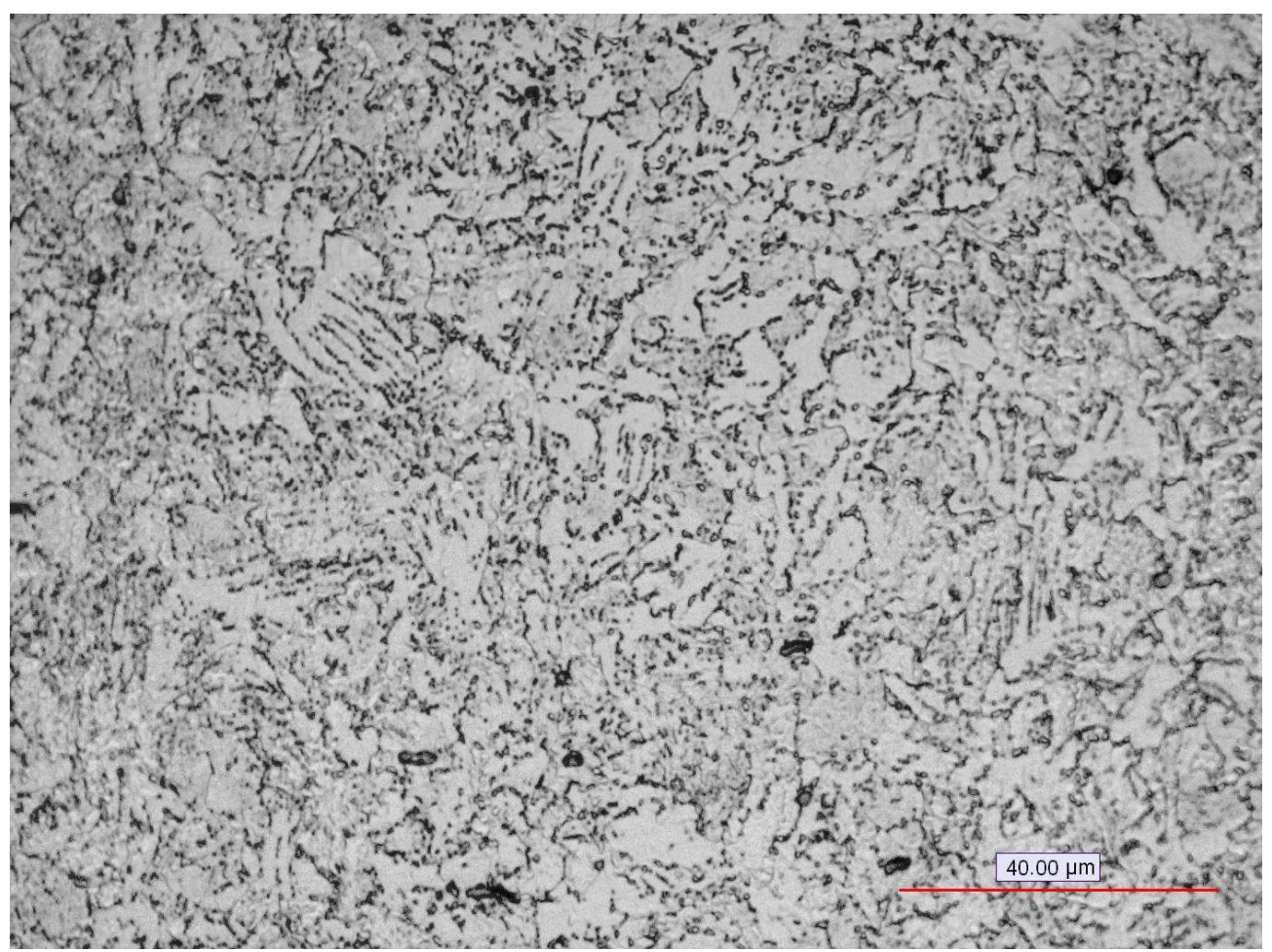

(a): Microstructure of the substrate

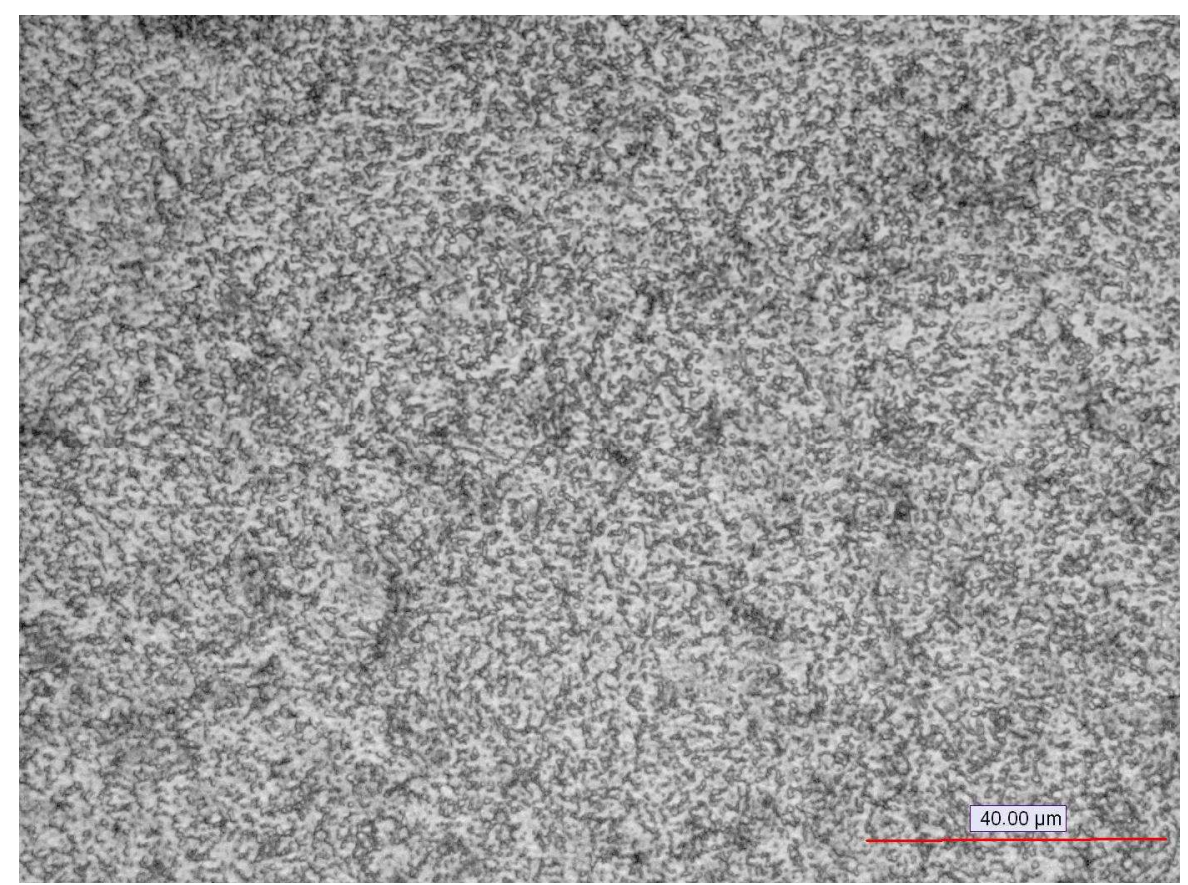

(b): Microstructure of the surface

FIG.7: microstructure of the carbonitrided not quenched C18 steel.

The hardness profile is given in Fig.8. The thicknesses $e_{1}$ and $e_{2}$ were considered respectively equal to 0.1 and $1 \mathrm{~mm}$. 


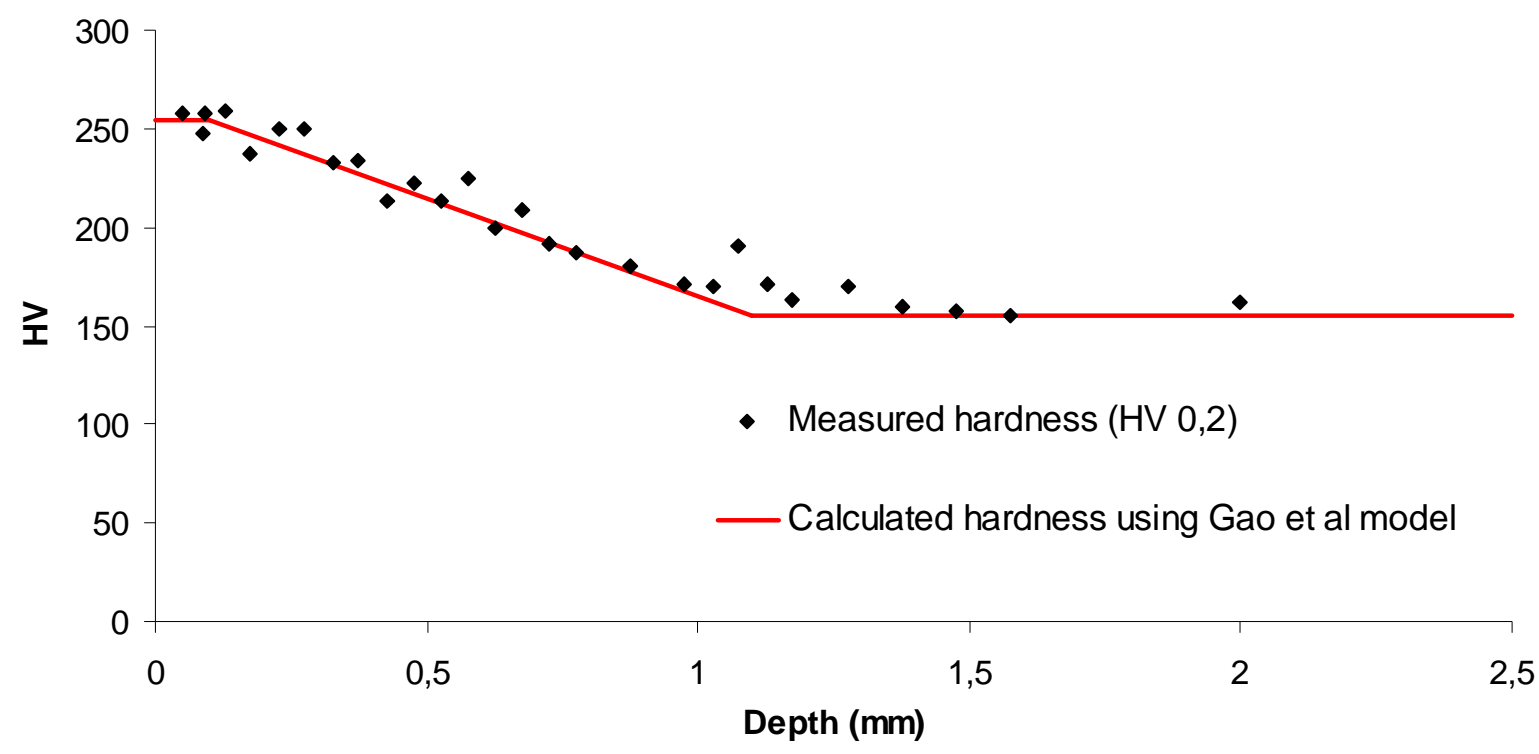

FIG. 8: Comparison between measured hardness and calculated hardness from plastic properties obtained using Gao et al. ${ }^{28}$ model for the carbonitrided not quenched C18 steel.

Figs. 9(a) and 9(b) show a comparison between experimental and numerical indentation curves for the substrate and the PGM respectively.

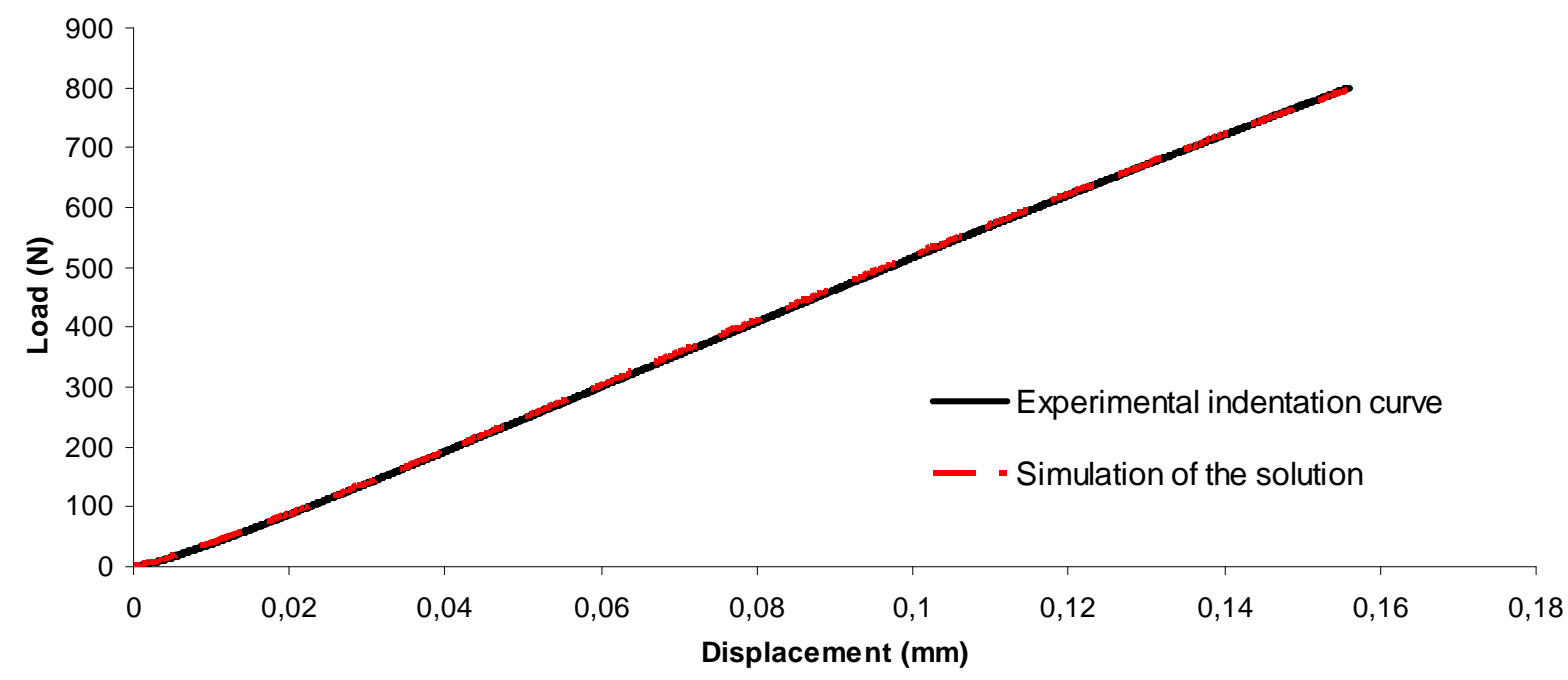

(a): substrate. 


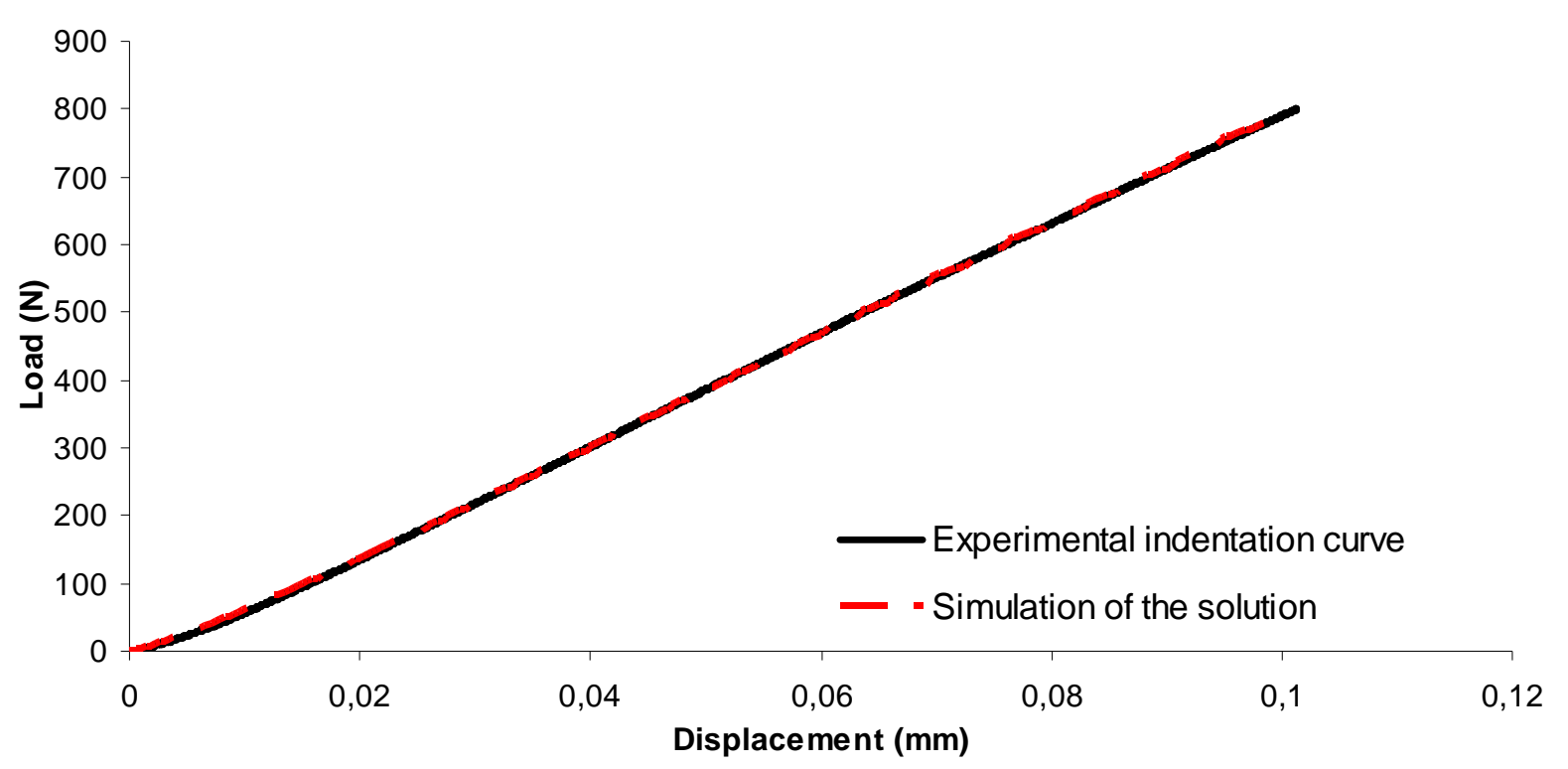

(b): surface

FIG.9: Comparison between experimental and numerical indentation curves for the carbonitrided not quenched $\mathrm{C} 18$ steel.

Figs. 9(a) and 9(b) show that the experimental and numerical indentation curves are very close.

The results obtained for the carbonitrided not quenched C18 steel are given in Table II.

\begin{tabular}{lll}
\hline & Substrate & Surface \\
$\sigma_{y}(\mathrm{MPa})$ & 233 & 460 \\
$\mathrm{n}$ & 0.198 & 0.200
\end{tabular}

TABLE II: Identification results obtained for the surface and substrate of the carbonitrided not quenched C18 steel.

Fig. 8 compares the Vickers profile calculated from the Gao et al. ${ }^{28}$ formulation with the measured one. This figure shows that the calculated hardness profile is in agreement with the measured one, which means that the obtained plastic properties seem correct.

\section{Carbonitrided C18 steel}

The second characterized PGM is a carbonitrided C18 steel. The same procedure described above was followed to characterize this material. The substrate of the carbonitrided $\mathrm{C} 18$ steel presents coarse acicular ferrite grains and pearlite (Fig.10(a)). Fig. 10(b) shows that the microstructure of the surface is composed of martensite needles. 


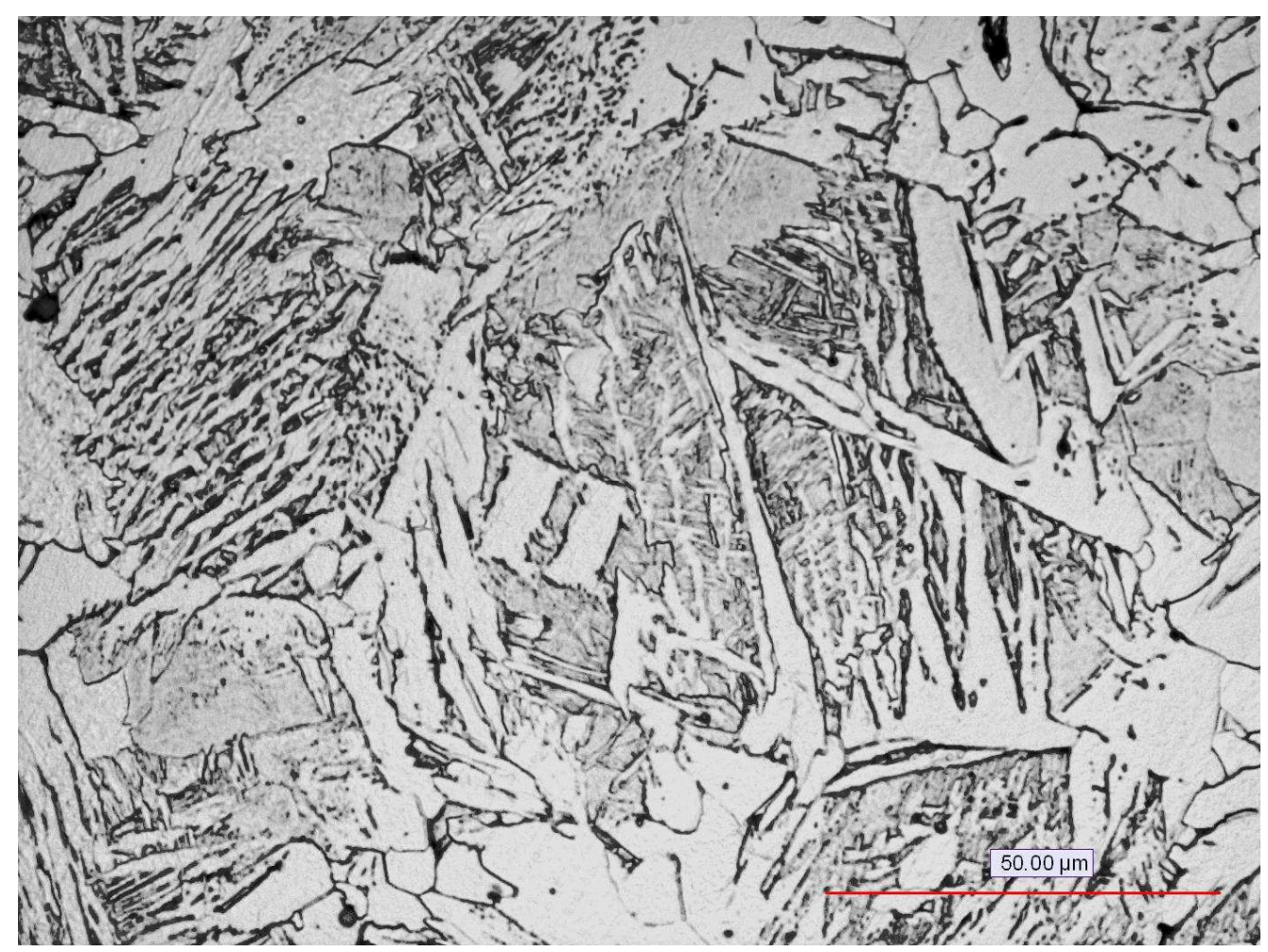

(a) : Substrate

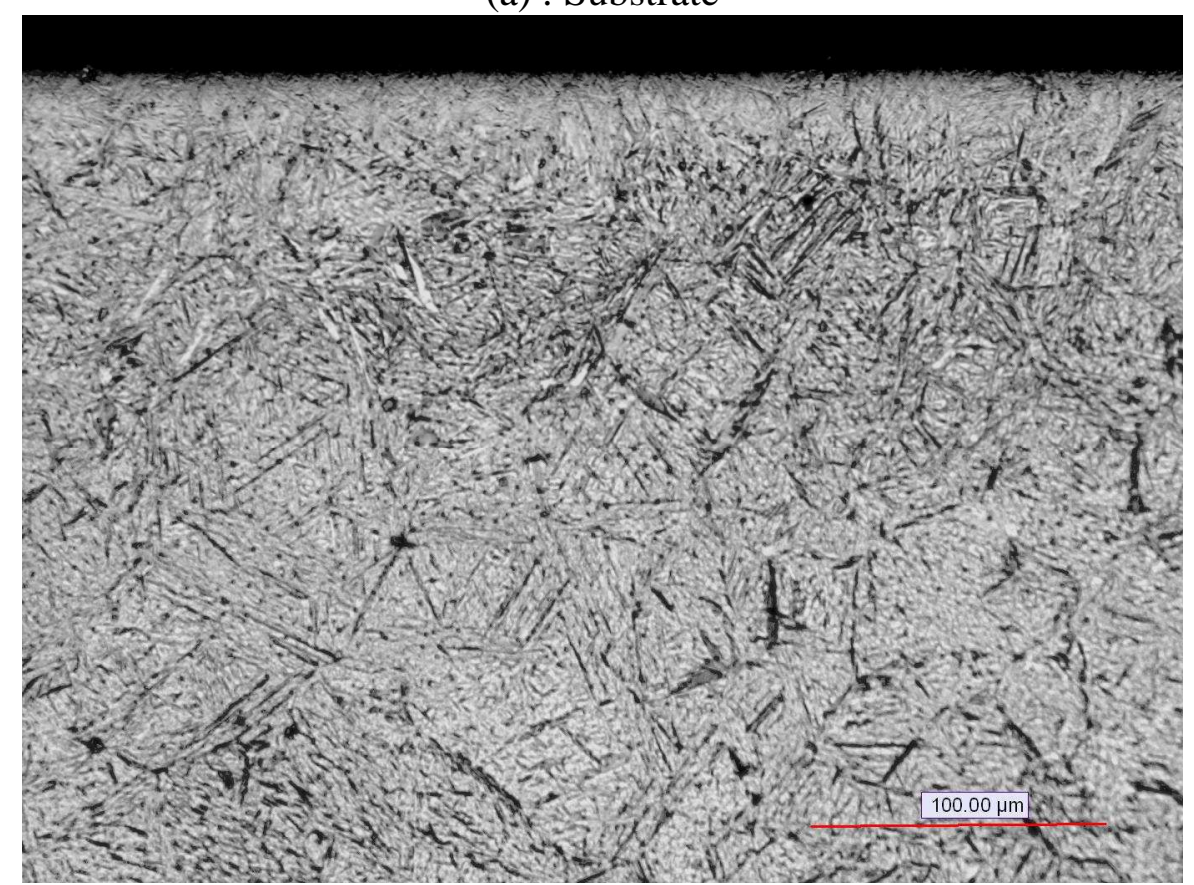

(b) : Surface

FIG.10: microstructure of the carbonitrided C18 steel.

The hardness profile is given on Fig. 11. The thicknesses $e_{1}$ and $e_{2}$ were considered respectively equal to 0.23 and $0.65 \mathrm{~mm}$. 


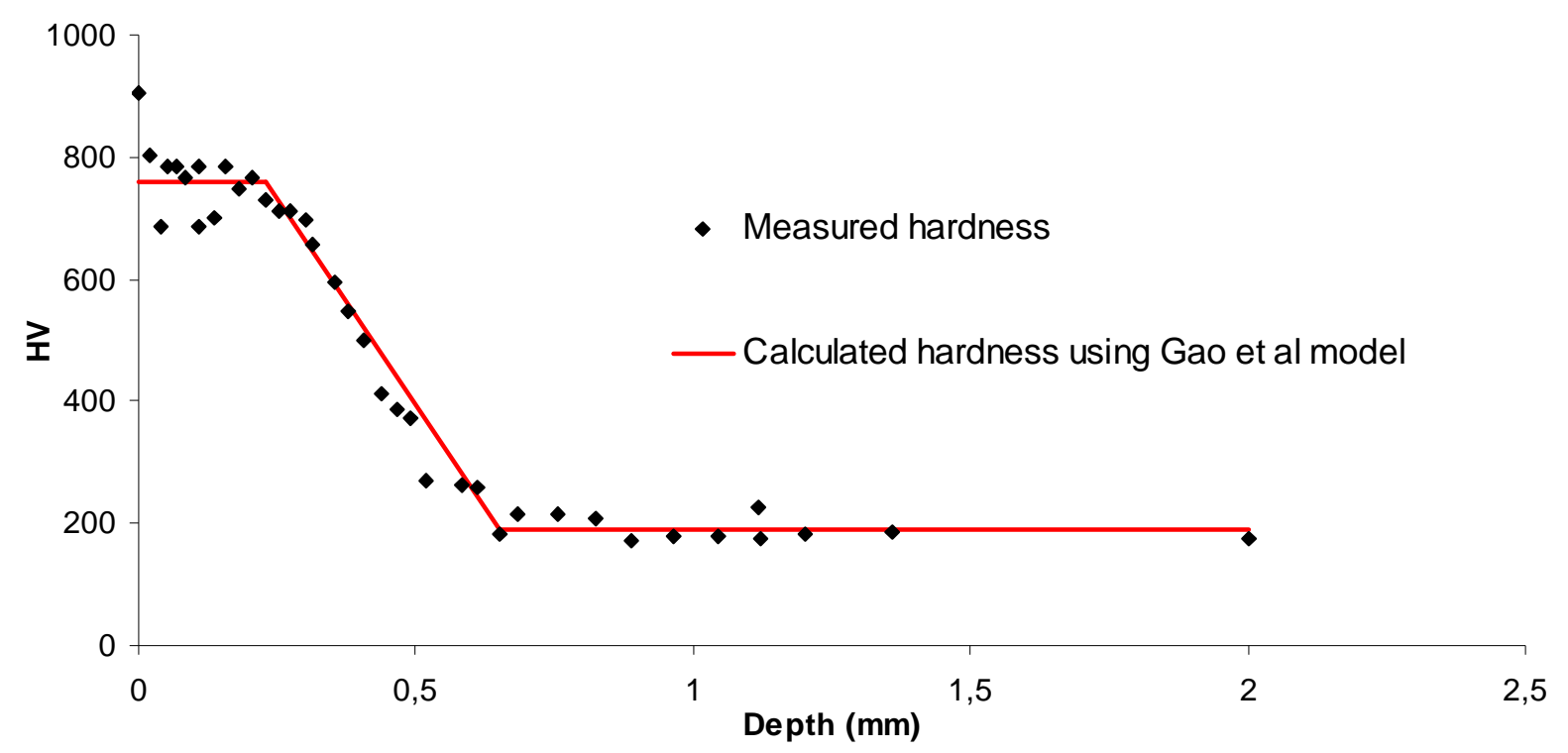

FIG.11: Comparison between measured hardness and calculated hardness from plastic properties obtained using Gao et al. ${ }^{28}$ model for the carbonitrided C18 steel.

Fig. 12(a) and 12(b) shows a comparison between experimental and numerical indentation curves for the substrate and the PGM respectively.

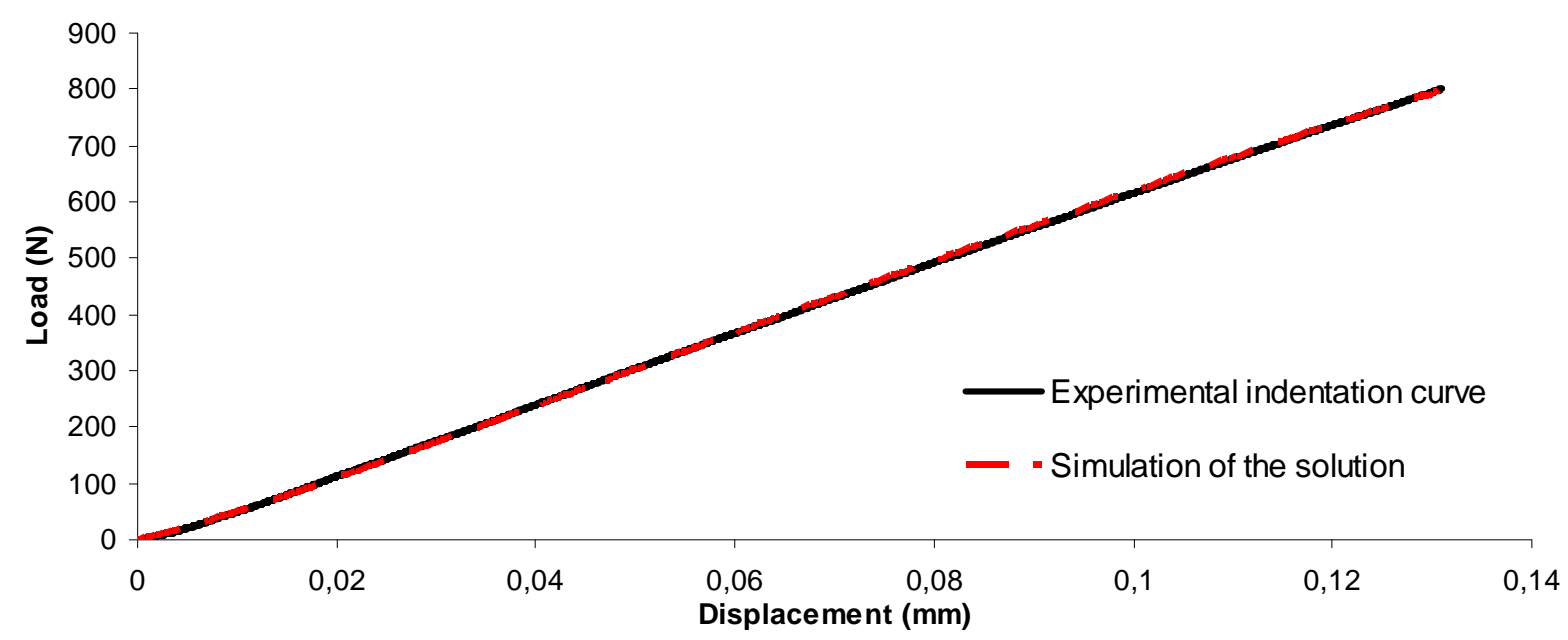

(a): substrate

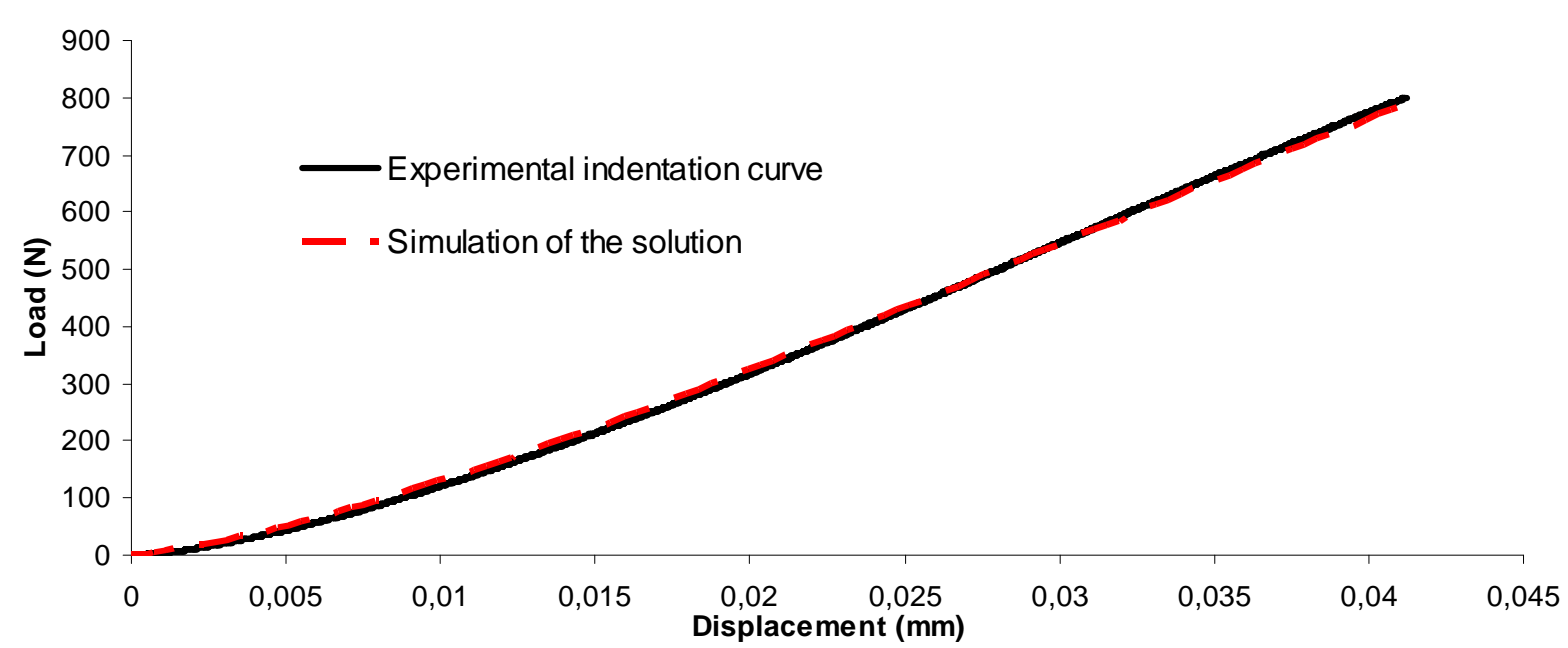


(b): surface

FIG.12: Comparison between experimental and numerical indentation curves for the carbonitrided $\mathrm{C} 18$ steel.

Fig. 12 show that the experimental and numerical indentation curves obtained for the substrate are very close. However, for the surface, a small difference between the experimental and numerical indentation curves is observed. Future work will be done to explain this difference.

The results of the carbonitrided C18 steel are given in Table III. We can conclude from these results that the assumption of the no variation of the strain hardening exponent $n$ is incorrect.

\begin{tabular}{lll}
\hline \hline & Substrate & Surface \\
$\sigma_{y}(\mathrm{MPa})$ & 379 & 2311 \\
$\mathrm{n}$ & 0,137 & 0,195 \\
\hline \hline
\end{tabular}

TABLE III: Identification results obtained for the surface and substrate of the carbonitrided C18 steel.

Fig. 11 compares the Vickers profile calculated from the Gao et al. formulation with the measured one. Despite the small difference between experimental and numerical indentation curves observed Fig. 12(b), Fig. 11 shows that the calculated hardness profile is close to the measured one. Hence, the results seem correct.

\section{Discussion}

As we can see in this section, the proposed method is reliable for the characterization of PGM. The results obtained for the two materials are in perfect agreement with the hardness profile. We can see clearly the effect of the treatment on the plastic properties. The assumption of the no variation of the strain hardening exponent, made in many studies, seems incorrect since the results obtained for the carbonitrided C18 steel present a variation in the strain hardening exponent $n$.

\section{CONCLUSION}

This paper presents a new procedure to determine plastic properties of PGM with inverse analysis using spherical indentation test data. In the first part, homogenous materials were characterized using this technique. Even if no proof of uniqueness has been provided, it can be noticed that the solution is independent from the starting point even if this one is very different from the solution. In the second part, a method to determine plastic properties of PGM was proposed. The first step of the proposed method is to perform an indentation test on the substrate and to characterize it using inverse analysis while considering the case of homogenous materials. Then, the thicknesses of the hardened layers are estimated from a hardness profile. Finally, an indentation test is performed on the hardened surface. This step leads to the determination of plastic properties of the different parts of the carbonitrided layers.

Carbonitrided not quenched C18 steel and carbonitrided C18 steel were characterized and the results obtained were verified with the hardness profile. The results show that the proposed method can be effectively employed to evaluate plastic properties of the carbonitrided layers. Spherical indentation using inverse analysis offers the possibility to evaluate mechanical properties of heat treated steels. 


\section{REFERENCES}

1. A. Nayebi, R. El Abdi, O. Bartier, G. Mauvoisin, New procedure to determine steel mechanical parameters from the spherical indentation technique. Mech. Mater. 34 (4), 243 (2002).

2. J.M. Collin, G. Mauvoisin, O. Bartier, R. El Abdi, P. Pilvin, Use of spherical indentation data changes to materials characterization based on a new multiple cyclic loading protocol. Mater. Sci. Eng. A 501, 608 (2009).

3. H. Lee, J.H. Lee, G.M. Pharr, A numerical approach to spherical indentation techniques for material property evaluation. J. Mech. Phys. Solids 53, 2037 (2005).

4. Y.P. Cao, J. Lu, A new method to extract the plastic properties of metal materials from an instrumented spherical indentation loading curve. Acta Mater. 52, 4023 (2004).

5. N. Ogasawara, N. Chiba, X. Chen, Measuring the plastic properties of bulk materials by indentation test. Scripta Mater. 54, 65 (2006).

6. M. Zhao, N. Ogasawara, N. Chiba, X. Chen, A new approach to measure the elasticplastic properties of bulk materials using spherical indentation. Acta Mater. 54, 23 (2006).

7. J.H. Lee, T. Kim, H. Lee, A study on robust indentation techniques to evaluate elasticplastic properties of metals. Int. J Solids Struct 47, 647 (2010).

8. P. Jiang, T. Zhang, Y. Feng, R. Yang, N. Liang, Determination of plastic properties by instrumented spherical indentation: Expanding cavity model and similarity solution approach. J. Mater. Res. 24 (3), 1045 (2009).

9. N. Ogasawara, N. Chiba, X. Chen, A simple framework of spherical indentation for measuring elastoplastic properties. Mech. Mater. 41, 1025 (2009).

10. T. Zhang, P. Jiang, Y. Feng, R. Yang, Numerical verification for instrumented spherical indentation techniques in determining the plastic properties of materials. J. Mater. Res. 24 (12),3653 (2009).

11. N.A. Branch, G. Subhash, N.K. Arakere, M.A. Klecka, A new reverse analysis to determine the constitutive response of plastically graded case hardened bearing steels. Int. J. Solids Struct.. 48, 584 (2011).

12. A.E. Giannakopoulos, Indentation of plastically graded substrates by sharp indentors. Int. J. Solids Struct.. 39, 2495 (2002).

13. I.S. Choi, M. Dao, S. Suresh, Mechanics of indentation of plastically graded materials-I: Analysis. J. Mech. Phys. Solids 56, 157(2008).

14. I.S. Choi, A.J. Detor, R. Schwiger, M. Dao, C.A. Schuh, S. Suresh, Mechanics of indentation of plastically graded materials-II: Experiments on nanocrystalline alloys with grain size gradients. J. Mech. Phys. Solids 56, 172 (2008).

15. M. Dao, N. Chollacoop, K.J. Van Vliet, T.A. Vankatesh, S. Suresh, Computational modeling of the forward and reverse problems in instrumented sharp indentation, Acta Mater. 49 (19), 3899 (2001).

16. D. Chicot, L. Gil, K. Silva, F. Roudet, E.S. Puchi-Cabrera, M.H. Staia, D.G. Teer, Thin film hardness determination using indentation loading curve modelling. Thin Solids Films 518, 5565 (2010). 
17. F. Zhang, R. Saha, Y. Huang, W.D. Nix, K.C. Hwang, S. Ku, M. Li, Indentation of a hard film on a soft substrate: Strain gradient hardening effects, Int. J. Plasticity. 23, 25 (2007).

18. M. Zhao, Y. Xiang, J. Xu, N. Ogasawara, N. Chiba, X. Chen, Determining mechanical properties of thin films from the loading curve of nanoindentation testing, Thin Solid Film 516, 7571 (2008).

19. J.A. Knapp, J.F. Browning, Nanoindentation characterization of ErT2 thin films, J. Nuclear Mater. 350, 147 (2006).

20. A. Nayebi, R. El Abdi, O. Bartier, G. Mauvoisin, Hardness profile analysis of elastoplastic heat-treated steels with a gradient in yield strength. Mater. Sci. Eng. A333, 160 (2002).

21. T. Nakamura, T. Wang, S. Sampath, Determination of properties of graded materials by inverse analysis and instrumented indentation. Acta Mater. 18, 4293 (2000).

22. T. Nakamura, Y. Gu, Identification of elastic-plastic anisotropic parameters using instrumented indentation and inverse analysis, Mech. Mater. 39, 340 (2007).

23. Y. Gu, T. Nakamura, L. Prchlik, S. Sampath, J. Wallace, Micro-indentation and inverse analysis to characterize elastic_plastic graded materials, Mater. Sci. Eng. A345, 233 (2003).

24. K.L. Johnson, Contact Mechanics, Cambridge University Press, London, 1985.

25. A.C. Fischer-Cripps, Critical review of analysis and interpretation of nanoindentation test data. Surf. Coat. Technol. 200, 4153 (2006).

26. M.R. VanLandingham, Review of instrumented indentation. Journal of Research of the National Institute of Standards and Technology 108, 249(2003).

27. A.K. Bhattacharya, W.D. Nix, Analysis of elastic and plastic deformation associated with indentation testing of thin films on substrates. Int. J. Solids Struc.. 24, 1287 (1988).

28. X.L. Gao, X.N. Jing, G. Subhash, Two new expanding cavity models for indentation deformations of elastic strain-hardening materials. Int. J. Solids Struct.. 43, 2193 (2006).

29. O. Bartier, X. Hernot, G. Mauvoisin, Theoretical and experimental analysis of contact radius for spherical indentation. Mech. Mater. 42, 640 (2010).

30. P. Pilvin, SiDoLo Version 2.5298, Notice d'utilisation, (2010).

31. V. Chean, E. Robin, R. El Abdi, P. Houizot, Use of the mark-tracking method for optical fiber characterization. Optic Laser tech. (2011). 